\title{
Tailoring the grain structure of IN718 during selective electron beam melting
}

\author{
Carolin Körner $^{1, \text { a }}$, Harald Helmer ${ }^{2}$, Andreas Bauereiß ${ }^{1}$, and Robert F. Singer ${ }^{1}$ \\ ${ }^{1}$ University of Erlangen-Nuremberg, WTM, 91058 Erlangen, Germany \\ ${ }^{2}$ University of Erlangen-Nuremberg, ZMP, 90762 Fürth, Germany
}

\begin{abstract}
Selective electron beam melting (SEBM) is an additive manufacturing method where complex parts are built from metal powders in layers of about $50 \mu \mathrm{m}$. SEBM works under vacuum conditions which results in a perfect protection of the metal alloy. The electron beam is used for heating (about $900{ }^{\circ} \mathrm{C}$ building temperature) and selective melting. The high beam velocities allow innovative scanning strategies in order to adapt the local solidification conditions which determine the epitaxial solidification process of IN718. We show how scanning strategies can be used either to produce a columnar grain structure with a high texture in building direction or a complete texture-free fine grained structure. Numerical simulations of the selective melting process are applied to reveal the fundamental mechanisms responsible for the completely different grain structures. In addition the influence of the different grain structures on the mechanical properties of IN718 is briefly discussed.
\end{abstract}

\section{Introduction}

Nowadays, industry and science are increasingly interested in additive manufacturing (AM) of metal powders and join their efforts to bring AM processes into commercial production [1]. Concerning powder based AM processes, there are still challenges to overcome like low build-up rates and a high anisotropy in mechanical proporties [24]. The build-up rate depends strongly on the deflection speed of the used heating source. In case of selective laser melting (SLM), a wide spread AM technique, a laser is used as a heating source and is moved by mechanical lenses resulting in a limitation of the maximum deflection speed. In selective electron beam melting (SEBM), an alternative AM technique, there are virtually no limitations with respect to the deflection speed, as the used electron beam is deflected by electromagnetic lenses, leading to deflection speeds $>6000 \mathrm{~m} / \mathrm{s}$ [5]. Besides higher buildup rates, high deflection speeds can also be used to alter the local solidification conditions in such a way that either columnar or equiaxed grain structures can be produced. In the current paper we discuss the influence of scanning strategies on the solidification conditions on base of experimental and numerical results.

\section{Experimental procedure}

\subsection{SEBM processing method}

In this study SEBM is used to build up specimens out of pre-alloyed metal power utilizing an Arcam $\AA$ A2 SEBM system with an acceleration voltage of $60 \mathrm{kV}$. The SEBM process operates under a controlled vacuum

${ }^{\mathrm{a}}$ Corresponding author: carolin.koerner@f au . de of $2 \times 10^{-3}$ mbar of $\mathrm{He}$ and starts on a starter plate, which is embedded in metal powder. Before starting the building process, the starter plate is heated to an elevated temperature which is characteristic for the processed material. The temperature is controlled by a thermocouple attached to the bottom side of the starter plate. After the desired temperature is reached, the building platform is lowered according to the desired layer thickness and a thin layer of powder particles is applied by the rake system. Afterwards, the loose powder particles are slightly sintered by heating with a strongly defocused beam to gain mechanical strength and electrical conductivity. During the final step, the pre-sintered powder layer is selectively molten by a focused electron beam. These process steps are repeated in each layer until the final 3D part is built up. To assure a firmly bonded connection between all layers, previously fabricated layers are remelted when successive layers are being fabricated [6].

\subsection{Material}

In this study argon gas atomized powder of the nickel-base superalloy Inconel 718 was used. The powder was supplied by TLS Technik GmbH, Bitterfeld. The nominal chemical composition is listed in Table 1.

Particle size analysis performed on a Malvern Mastersizer 3000 shows a particle size distribution mostly between 45 and $105 \mu \mathrm{m}$. As starter plate, a $10 \mathrm{~mm}$-thick polycrystalline IN718 disk was used with a composition within the specification according to AMS 5662.

\subsection{Experimental setup}

Experiments consisting of building 9 cube shaped samples $\left(15 \times 15 \times 10 \mathrm{~mm}^{3}\right)$ were performed with five deflection

This is an Open Access article distributed under the terms of the Creative Commons Attribution License 4.0, which permits unrestricted use, distribution, and reproduction in any medium, provided the original work is properly cited. 
Table 1. Nominal composition of gas atomized Inconel 718 powder (in wt. \%).

\begin{tabular}{|l|l|l|l|l|l|l|}
\hline Element & $\mathrm{Ni}$ & $\mathrm{Mo}$ & $\mathrm{Fe}$ & $\mathrm{Cr}$ & $\mathrm{Nb}$ & $\mathrm{Al}$ \\
\hline wt. \% & $\mathrm{Bal}$. & 3.04 & 17.8 & 18.25 & 5.44 & 0.52 \\
\hline Element & $\mathrm{Ti}$ & $\mathrm{Co}$ & $\mathrm{C}$ & $\mathrm{N}$ & $\mathrm{O}$ & \\
\hline wt. $\%$ & 0.93 & 0.34 & 0.02 & 0.006 & 0.009 & \\
\hline
\end{tabular}

a) cross snake (CS)

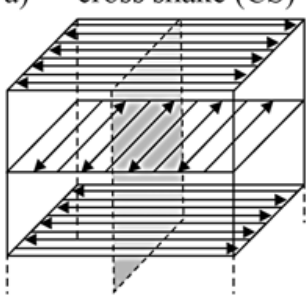

b) cross snake ten $(\mathrm{CS} 10)$

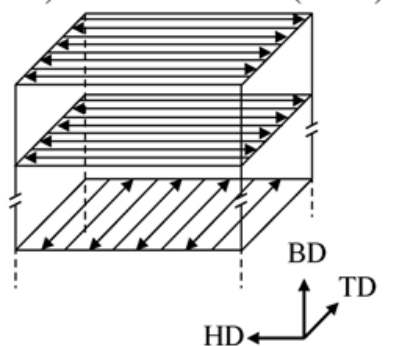

Figure 1. Scanning strategies cross snake (CS) a) and cross snake ten $(\mathrm{CS} 10) \mathrm{b}$ ). In snake mode the beam moves back and forth in hatching direction (HD). In CS10 the hatching direction is changed after each tenth layer. For microstructural investigations specimens were cut parallel to the building (BD) and to the traverse direction (TD), as indicated by the plane shown in grey in a).

speeds $\mathrm{v}$ from $2.2 \mathrm{~m} / \mathrm{s}$ to $8.8 \mathrm{~m} / \mathrm{s}$ and a beam power $\mathrm{P}$ $594 \mathrm{~W}$. For each deflection speed the distance between beam lines, i.e. the line offset $\mathrm{L}_{\text {Off, }}$, was adapted in such a way that the total layer hatching time (time of irradiation by the beam) is kept constant for all experiments resulting in a constant area energy EA:

$$
\mathrm{EA}=\mathrm{P} /\left(\mathrm{v} * \mathrm{~L}_{\mathrm{Off}}\right) .
$$

For the three highest deflection speeds two additional powers $(\mathrm{P}=447 \mathrm{~W} \& 513 \mathrm{~W})$ were investigated.

Experiments were performed with a focused beam (spot diameter $\sim 350-400 \mu \mathrm{m}$ ) and with a cross snake scanning strategy, where the electron beam moves in a back and forth pattern during hatching. In addition, the hatching direction is rotated by $90^{\circ}$ after each layer, see Fig. 1a).

Besides cross snake (CS), the scanning strategy cross snake ten (CS10) was used at a deflection speed of $8.8 \mathrm{~m} / \mathrm{s}$, see Fig. 1b. CS10 is quite similar to cross snake, although the hatching direction is changed by $90^{\circ}$ after ten layers, not after each layer.

The preheating parameters were held constant for all building processes and lead to a building temperature of $\sim 900^{\circ} \mathrm{C}$. All specimens were fully dense.

\subsection{Evaluation of the grain structure}

The grain structure of all samples was analysed with a scanning electron microscope (SEM) in BSE mode. The grain width and length were measured using the intercept method parallel and transverse to the building direction, respectively, in a total area of $1.02 \mathrm{~mm}^{2}$. In the plane of observation grains are elongated parallel to the building direction (Fig. 1). The measurements were always
Table 2. Parameter sets used for tensile test specimens.

\begin{tabular}{|l|l|l|}
\hline Microstructure & Parameter Sets & Area energy \\
\hline Columnar & $\mathrm{v}=4.5 \mathrm{~m} / \mathrm{s} \&$ & $\mathrm{EA}=1.8 \mathrm{~J} / \mathrm{mm}^{2}$ \\
& $\mathrm{~L}_{\text {Off }}=100 \mu \mathrm{m}$ & \\
\hline Equiaxed & $\mathrm{v}=8.8 \mathrm{~m} / \mathrm{s} \&$ & $\mathrm{EA}=1.8 \mathrm{~J} / \mathrm{mm}^{2}$ \\
& $\mathrm{~L}_{\text {Off }}=37.5 \mu \mathrm{m}$ & \\
\hline
\end{tabular}

conducted at the same building height and position, i.e. $1 \mathrm{~mm}$ below the top surface and near the centre of the longitudinally cut samples. The grain aspect ratio $\mathrm{R}$ is calculated from the average grain length $\mathrm{L}$ (in $\mathrm{m}$ ) and the average grain width $\mathrm{W}$ (in $\mathrm{m}$ ) as follows (1):

$$
\mathrm{R}=\mathrm{L} / \mathrm{W} .
$$

A grain aspect ratio of one indicates an equiaxed grain morphology. With increasing $\mathrm{R}$ the columnar character of the microstructures increases.

\subsection{Tensile test}

Tensile test were performed to evaluate the influence of a columnar or equiaxed microstructure on the mechanical properties. For tensile tests 40 SEBM samples were fabricated with two different parameter sets, listed in Table 2.

Tests were performed with cylindrical sample geometry with $6 \mathrm{~mm}$ in diameter and $35 \mathrm{~mm}$ in gauge length, according to DIN50125. Test samples were homogenized at a temperature of $1060{ }^{\circ} \mathrm{C}$ for 2 hours and annealed at $720^{\circ} \mathrm{C}$ and $620^{\circ} \mathrm{C}$ for 8 hours each. The homogenization temperature of $1060^{\circ} \mathrm{C}$ is above $\delta$ solvus temperature of $\sim 1010^{\circ} \mathrm{C}$, resulting in a complete dissolution of the $\delta$ phase [7]. Tensile tests were performed at room temperature (RT) and at $650{ }^{\circ} \mathrm{C}$ with loading directions parallel and perpendicular to the building direction. For each parameter set, temperature and loading direction five tensile tests were performed.

\section{Numerical simulations}

The resulting microstructure is governed by the conditions during melting and solidification, especially the level and direction of the thermal gradient at the solidification front. We use numerical simulation in order to understand the correlation between scanning strategy, resulting solidification conditions and microstructure. The numerical model (based on the Lattice Boltzmann Method) which we have developed for simulation of powder bed based additive manufacturing processes has been described in several publications [8-15]. The beam melting process is simulated on the powder scale, i.e. the stochastics of the powder bed is fully taken into account, see Fig. 2. The numerical model solves full hydrodynamics in the melt pool and thermodynamics in the entire domain. The liquidatmosphere surface is tracked implicitly by a volume of fluids method. Effects such as absorption of the electron beam, phase transitions and wetting and dewetting of single powder particles are captured by the model. 


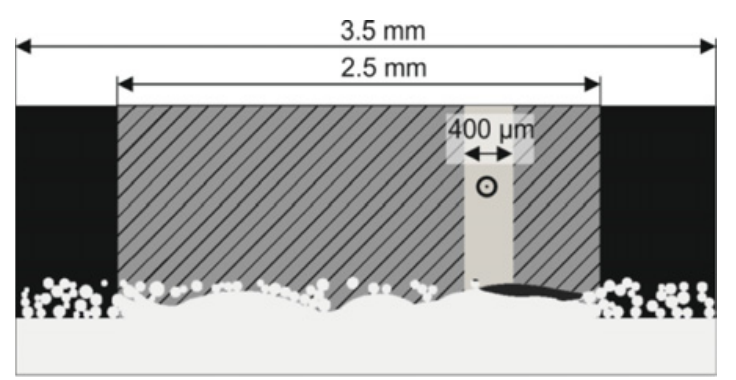

Figure 2. Screenshot of the numerical simulation. Powder (white) is molten by an electron beam (light gray) in the shaded area. The beam traverses primarily the simulation plane (dark gray) according to Fig. 1. In the liquid melt pool (dark area underneath the beam) full fluid dynamics is solved.

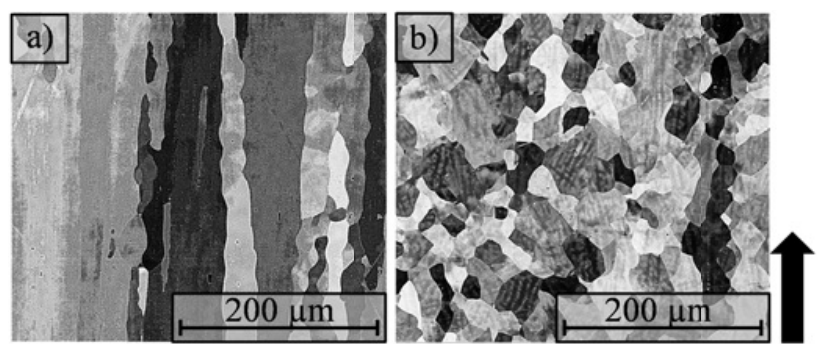

Figure 3. SEM-micrograph showing a columnar grain structure a) and an equiaxed grain structure b) in a longitudinal section parallel to the building direction, indicated by the black arrow (beam parameters: $\mathrm{EA}=1.8 \mathrm{~J} / \mathrm{mm}^{2}$, a) $\mathrm{v}=2.2 \mathrm{~m} / \mathrm{s} \& \mathrm{~L}_{\mathrm{Off}}=$ $\left.150 \mu \mathrm{m} \mathrm{b}) \mathrm{v}=8.8 \mathrm{~m} / \mathrm{s} \& \mathrm{~L}_{\mathrm{Off}}=37.5 \mu \mathrm{m}\right)$.

In this paper we use the $2 \mathrm{D}$ version of our model in order to simulate hatching processes where several layers are built consisting of many melt lines. The numerical setup is depicted in Fig. 2. An area of $2.5 \mathrm{~mm} \times 15 \mathrm{~mm}$ is scanned by the electron beam. Due to methodic restrictions, the hatching direction of the electron beam is changed by $180^{\circ}$ in each layer rather than $90^{\circ}$ as depicted in Fig. 1a. The parameters for the numerical experiments are adjusted to the experiments: $\mathrm{EA}=1.8 \mathrm{~J} / \mathrm{mm}^{2}: \mathrm{v}=$ $8.8 \mathrm{~m} / \mathrm{s} \& \mathrm{~L}_{\mathrm{Off}}=37.5 \mu \mathrm{m}, \mathrm{v}=6.6 \mathrm{~m} / \mathrm{s} \& \mathrm{~L}_{\mathrm{Off}}=50 \mu \mathrm{m}$ and $\mathrm{v}=2.2 \mathrm{~m} / \mathrm{s} \& \mathrm{~L}_{\mathrm{Off}}=150 \mu \mathrm{m} ; \mathrm{EA}=1.35 \mathrm{~J} / \mathrm{mm}^{2}$ : $\mathrm{v}=6.6 \mathrm{~m} / \mathrm{s} \& \mathrm{~L}_{\mathrm{Off}}=50 \mu \mathrm{m}$.

\section{Results and discussion}

\subsection{Influence of beam deflection speed and line offset on grain aspect ratio}

Figure 3a shows a typical columnar microstructure which is obtained after additive manufacturing with SEBM with a standard cross snake scanning strategy and slow beam parameters. The columnar microstructure with a strong texture in building direction results from epitaxial growth and steep temperature gradients mostly parallel to the building direction $[2-4,16]$. With the same area energy but lower line offset and higher deflection speed the grain structure becomes equiaxed, see Fig. $3 b$.

Figure 4 shows the average grain ratio as a function of the line offset for different area energies.

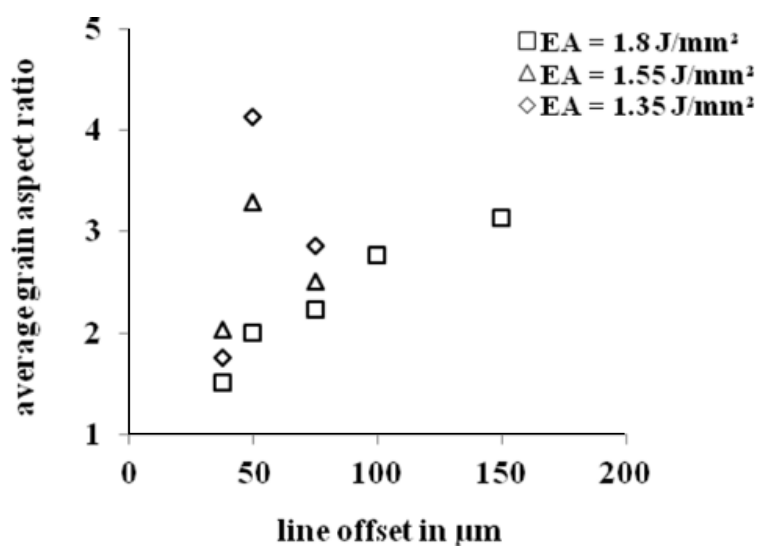

Figure 4. Average grain aspect ratio as a function of the line offset. For the lowest line offset the aspect ratio varies from 1.5 to 2.1 with the lowest value for the highest area energy.

Deflection speed $\mathrm{v}$ and line offset $\mathrm{L}_{\mathrm{Off}}$ are adjusted in such a way that the total time of irradiation for one plane is constant: $v \sim 1 / \mathrm{L}_{\text {Off. }}$ High deflection speeds and low line offsets mean more frequent multi-passing of the same area, as long as $\mathrm{L}_{\mathrm{Off}}$ is smaller than the beam diameter. That is, the energy is deposited in an incremental way within the melting area. The lowest aspect ratio with a value of 1.5 corresponding to almost equiaxed grains is observed for the lowest line offset, i.e. highest deflection speed v.

The effect of the deflection speed and line offset on the melt pool geometry and the solidification conditions is investigated by numerical simulation. In Figs. 5a, b, d, e maps of the solidification streamlines and the temperature gradient at the solidification front are depicted.

At high line offsets and low deflection speeds the electron beam creates a melt pool which follows the beam back and forth within the hatching area, see Fig. 1d. This leads to the more spherical melt pool borders, see Fig. 5b, typically observed in the microstructure in longitudinal cross section views [2-4,16,17].

At low line offset and high deflection speed individual melt pools vanish more and more and are replaced by more or less flat lines indicating the individual layers, see Figs. 6e, f. In this case not an isolated single melt pool but a melt line transverse to the hatching direction over several line segments is created during hatching (beam parameters: $\mathrm{v}=8.8 \mathrm{~m} / \mathrm{s} \& \mathrm{~L}_{\text {Off }}=37.5 \mu \mathrm{m}$ ).

As heat is conducted into the solid during solidification the melt pool geometry defines the direction of the steepest temperature gradients. The observed effect of the line offset and deflection speed on the melt geometry leads to a change in the direction of the temperature gradient and as a consequence to a change in the preferred crystallographic growth direction. With decreasing line offset the temperature gradient at the solidification front gets smaller. In addition, the spatial variations of the temperature gradient decrease. On the other hand, the direction changes of the solidification streamlines strongly increase with decreasing line offset. At high line offsets the steepest temperature gradients stay more or less parallel to the building direction producing the typical columnar microstructure like in Fig. 3a. At low line offsets the temperature gradients are tilted away from the building 
a)

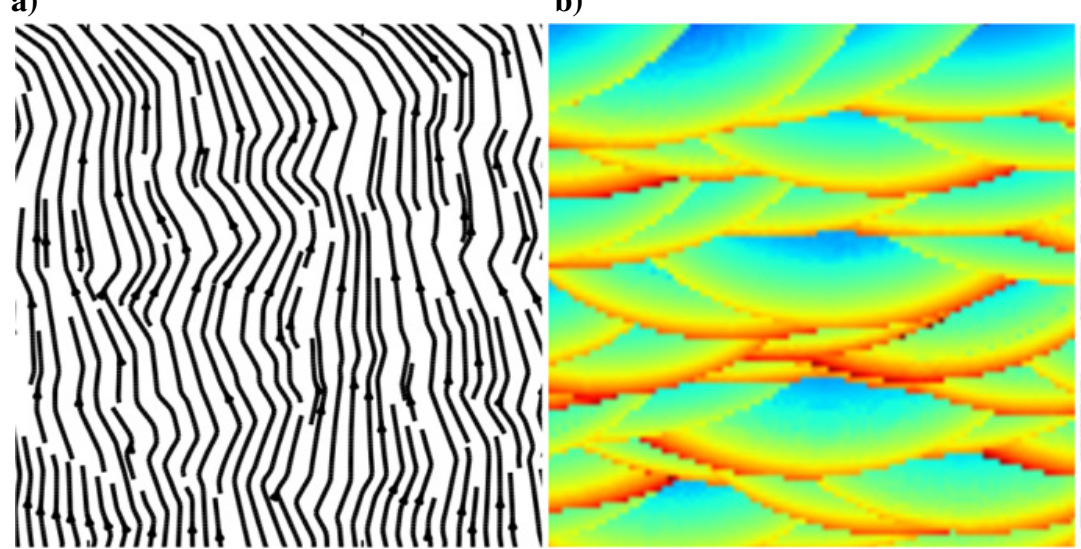

d)

e) b)

c)

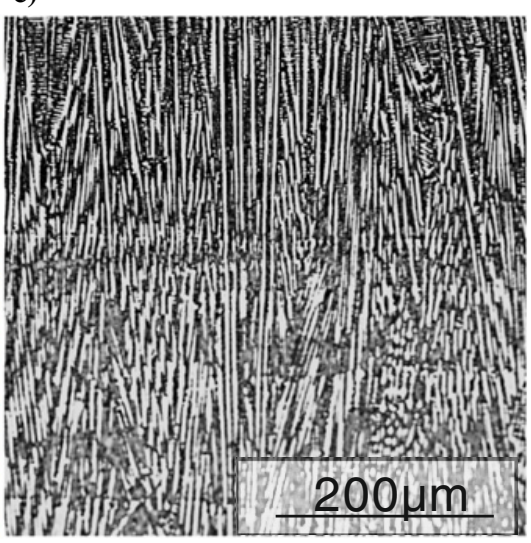

f)

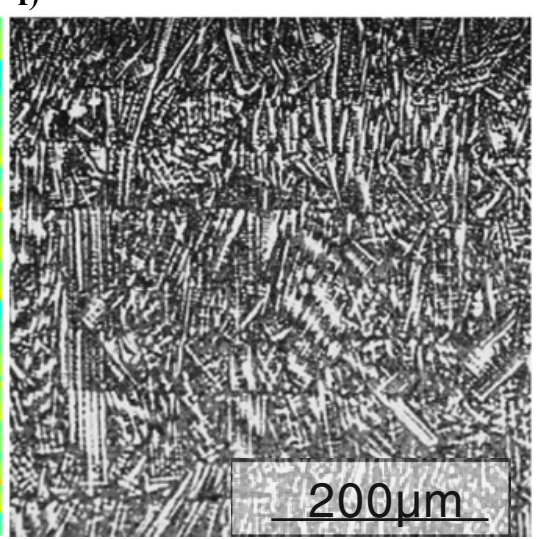

Figure 5. Experimental results with their numerical counterparts for low deflection speed and high line offset in a-c) and for high deflection speed and low line offset in $\mathrm{d}-\mathrm{f}$ ) (beam parameters: $\mathrm{a}-\mathrm{f}$ ) $\mathrm{EA}=1.8 \mathrm{~J} / \mathrm{mm}^{2} ; \mathrm{a}-\mathrm{c}$ ) $\mathrm{v}=2.2 \mathrm{~m} / \mathrm{s} \& \mathrm{~L}_{\text {Off }}=150 \mu \mathrm{m}$ and $\mathrm{d}-\mathrm{f}$ ) $\mathrm{v}=8.8 \mathrm{~m} / \mathrm{s} \& \mathrm{~L}_{\text {Off }}=37.5 \mu \mathrm{m}$ ). In a) and d) the direction of the temperature gradient, i.e. the solidification direction, can be seen as streamlines. For high deflection speeds (d) the temperature gradient moves in zigzag from one layer to the other. For low deflection speeds in a) the stream lines are more parallel to the building direction. The experimental counterparts show a similar melt pool shape as the numerical results. For high deflection speeds in f) melt pool borders are nearly flat. For low deflection speeds in c) spherical melt pool borders are visible.

direction towards the traverse direction of each layer resulting in strong deviations from the building direction. This finding becomes even clearer with the help of respective histograms, see Fig. 6. For the high line offset most temperature gradients are near BD. The deviation of the direction of the temperature gradients varies from $0^{\circ}$ to approximately $80^{\circ}$ with a clear maximum at $0^{\circ}$ corresponding to the building direction.

For low line offsets the deviation of the temperature gradients to BD has two maximum peaks at $+\alpha$ and $-\alpha$, see Figs. $6 b$ and c. Looking on a grain with its $<100>$ crystallographic growth direction parallel aligned to the building direction, a deviation of $45^{\circ}$ causes a maximum disturbance of the epitaxial growth. As the grain will fall behind with respect to the solidification front into regions with more undercooling nucleation of new grains may be facilitated [18].

For lower area energies higher aspect ratios are found for constant parameter sets, see Fig. 4. This can also be explained by the orientation of the temperature gradient. Comparing simulations for a deflection speed of $6.6 \mathrm{~m} / \mathrm{s}$ and a line offset of $50 \mu \mathrm{m}$, the applied area energy has an influence on the deviation of the temperature gradient, as well. Here, for an area energy of $1.35 \mathrm{~J} / \mathrm{mm}^{2}$ the deviation of the temperature gradient to the BD shows a clear maximum around $0^{\circ}$ in the histogram, see Fig. 7 . Increasing the area energy to $1.8 \mathrm{~J} / \mathrm{mm}^{2}$ with an identical parameter set leads to a histogram where two peaks can be detected, see Fig. 6b. Again, the stronger deviation of the temperature gradient from the building direction leads to a lower aspect ratio.

\subsection{Influence of the scanning strategy on the grain structure}

The parameter set resulting in equiaxed grains with the scanning strategy "cross snake" was tested with the scanning strategy "cross snake ten" again (beam parameters: $\left.\mathrm{v}=8.8 \mathrm{~m} / \mathrm{s} \& \mathrm{~L}_{\mathrm{Off}}=37.5 \mu \mathrm{m}\right)$. In contrast to the standard scanning strategy "cross snake", the grain structure can be divided into regions with high and low aspect ratios in CS10 where the direct direction changes after 10 layers. Figure 8 shows the microstructure of the CS10 experiment with regions of columnar grains interrupted by layers of equiaxed grains. Stray grains occur more or less every tenth layer which is equivalent to the layer where the hatching direction is changed by $90^{\circ}$. In addition, the growth direction of the columnar grains 
a)

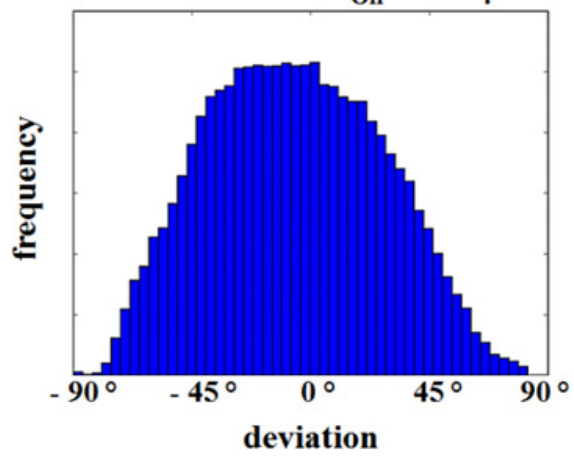

b)

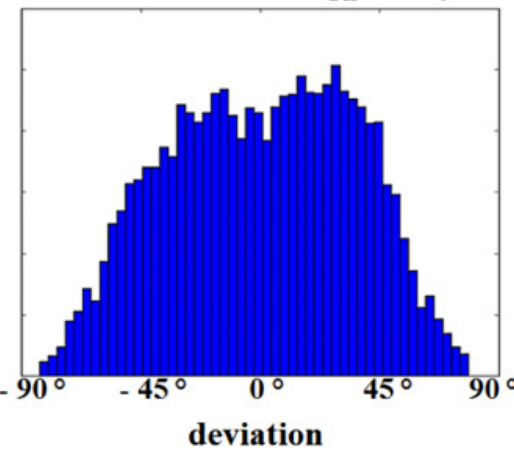

c) $\mathrm{v}=8.8 \mathrm{~m} / \mathrm{s} \& \mathrm{~L}_{\mathrm{Off}}=37.5 \mu \mathrm{m}$

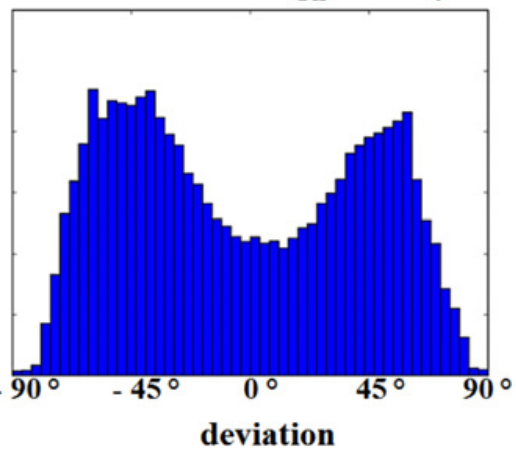

Figure 6. Histograms of the temperature gradients at the solidification front with respect to the building direction for an EA of $1.8 \mathrm{~J} / \mathrm{mm}^{2}$. With high line offset (low deflection speeds) in a) the thermal gradient shows its maximum at $0^{\circ}$. With decreasing line offset (and higher beam deflection speed) in b) and c) the temperature gradient becomes more and more tilted in every layer resulting in two peaks at $+\alpha$ and $-\alpha$.

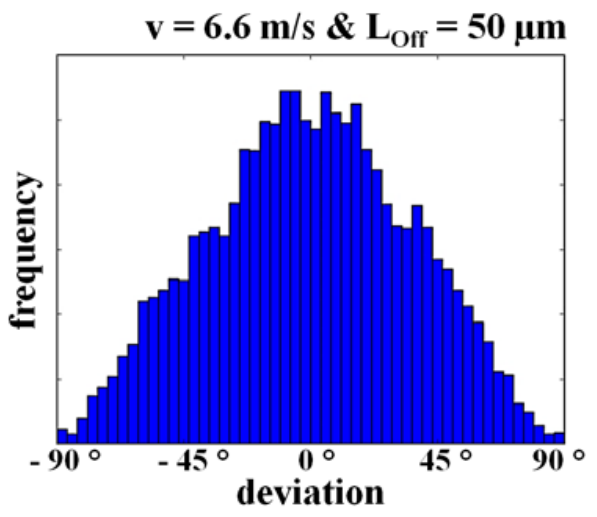

Figure 7. Histogram of the temperature gradient at the solidification front for a deflection speed of $6.6 \mathrm{~m} / \mathrm{s}$, a line offset of $50 \mu \mathrm{m}$ and an area energy of $1.35 \mathrm{~J} / \mathrm{mm}^{2}$.

changes after changing the hatching direction. Obviously, the rotation of $90^{\circ}$ after ten layers rather than after every layer has strong influence on the solidification conditions and the resulting grain structure. In regions with constant hatching direction columnar grains are tilted to some degree, indicating a grain selection process with the steepest temperature gradient tilted to BD.

Every change of the hatching direction is accompanied by a change of the melt pool orientation perpendicular to the hatching direction and with it, by an orientation change of the temperature gradients. A change of the hatching direction results in different preferred growth direction of the current layer with respect to the previous one. Due to this, grains solidified in the previous layer can be misorientated with respect to the steepest temperature gradients in the next layer, leading to a higher tendency to form stray grains.

\subsection{Mechanical properties}

The mechanical properties of SEBM IN718 have been evaluated in tensile tests parallel and perpendicular to building direction at room temperature (RT) and $650^{\circ} \mathrm{C}$ for equiaxed and columnar grain structures, see Fig. 9. The minimum requirements at $\mathrm{RT}$ of the aerospace

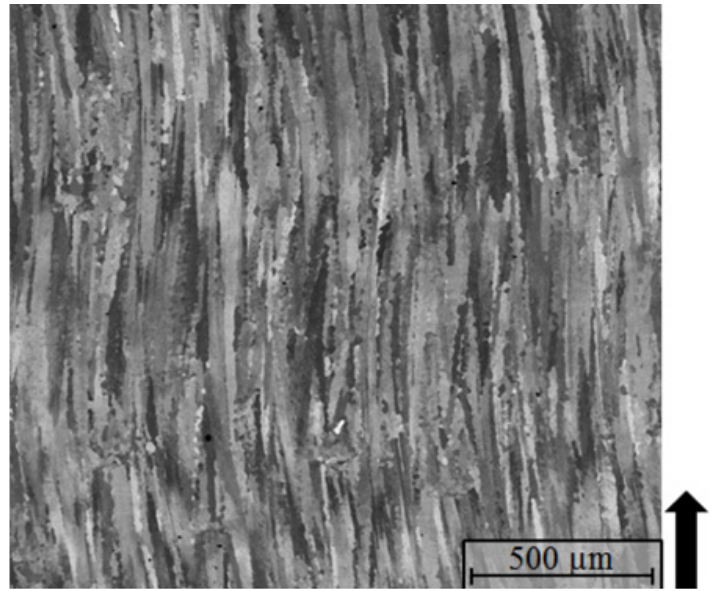

Figure 8. SEM-micrograph in a longitudinal section of cross snake 10 scanning strategy showing tilted columnar grains interrupted by a more equiaxed region every 10 layers.

material specification (AMS) $6552 \mathrm{G}$ for wrought IN718 are $1030 \mathrm{MPa}$ in $0.2 \%$ yield strength (YS), $1275 \mathrm{MPa}$ in ultimate tensile strength (UTS) and $12 \%$ in elongation to failure $(\varepsilon)$. These are met for the columnar microstructure in all tests. For the equiaxed microstructure only the yield strength lies within the requirements of AMS 6552G. In addition, only one tensile test specimen could be evaluated at a loading direction parallel to the building direction (RT).

The microstructural adaption during SEBM shows the strongest effect on the Young's modulus. Here, an almost isotropic Young's modulus of $183 \mathrm{GPa}$ and $189 \mathrm{GPa}$ can be found for equiaxed test specimens in parallel and perpendicular loading direction, respectively. Columnar test specimens do show a strong anisotropy with either $127 \mathrm{GPa}$ in parallel or $159 \mathrm{GPa}$ in perpendicular loading direction. This is due to the grain orientation in columnar specimens with grains being elongated in the crystallographic [100] direction parallel to the building direction. In parallel loading direction the Young's modulus equals the Young's modulus of $\mathrm{Ni}$ in $\langle 100\rangle$. In perpendicular loading direction grains are orientated in 


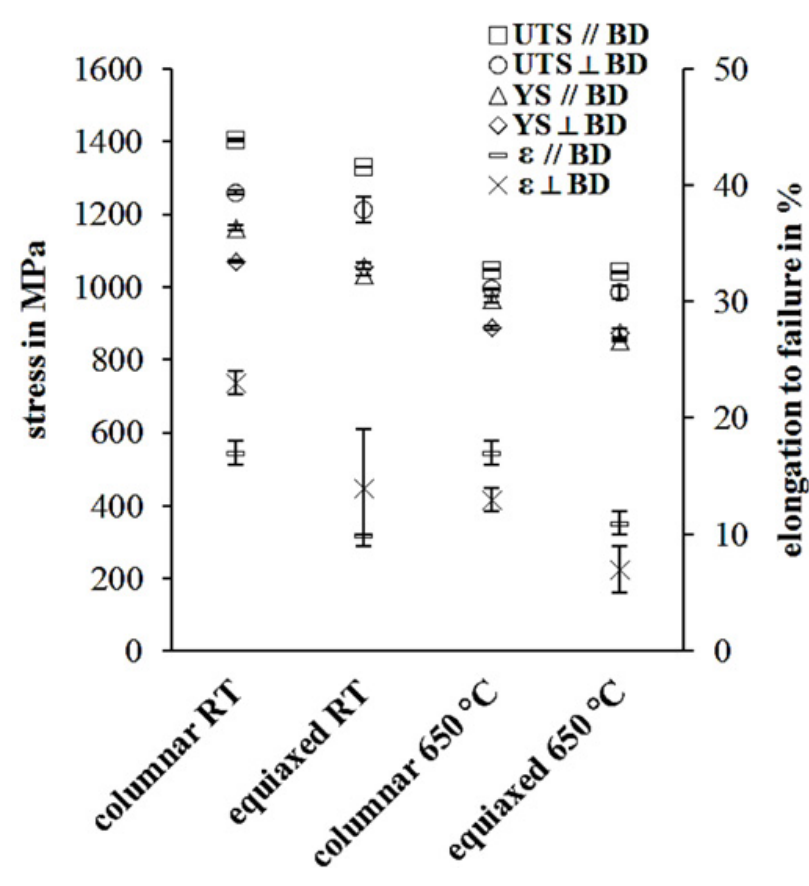

Figure 9. Mechanical properties of tensile test specimens with columnar and equiaxed grain structure at room temperature (RT) und $650{ }^{\circ} \mathrm{C}$ with loading directions parallel $(/ /)$ and perpendicular $\left.{ }_{(-}\right)$to the building direction. AMS $6552 \mathrm{G}$ is met for ultimate tensile strength (UTS) and yield strength (YS), but not for elongation to failure $(\varepsilon)$ for specimens with equiaxed grain structure.

$\langle 100\rangle$ or $\langle 110\rangle$ directions or in between, resulting in higher Young's modulus of $159 \mathrm{GPa}$.

\section{Conclusion}

The grain structure of IN718 samples produced by SEBM can be influenced by the scanning strategy during melting. Strongly columnar and nearly equiaxed grain structures are observed. The grain structure has strong influence on the mechanical properties. Numerical simulation of the SEBM process has proven to be essential to reveal the origin of the different microstructures. A strong variation of the solidification direction between successive layers provokes equiaxed microstructures whereas columnar grains result if solidification is mainly in building direction. This result shows that local tailoring of the grain structure of a component is possible by varying the scanning strategy.

The authors gratefully acknowledge funding by the Deutsche Forschungsgemeinschaft (DFG) through the Collaborative Research Center (SFB), Transregio 103, project B2 and through the SFB 814, project B4.

\section{References}

[1] N. Hopkinson, R. Hague, P. Dickens, An Industrial Revolution for the Digital Age, Wiley (2006)

[2] G. P. Dinda, A. K. Dasgupta, J. Mazumder, Mater. Sci. Eng. A 509 (1-2), 98 (2009)

[3] L. Thijs, K. Kempen, J. P. Kruth, J. van Humbeeck, Acta Mater. 61 (5), 1809 (2013)

[4] L. E. Murr, S. M. Gaytan, D. A. Ramirez, E. Martinez, J. Hernandez, K. N. Amato, et al., J. Mater. Sci. Technol. 28 (1), 1 (2012)

[5] ARCAM AB, Sweden, Arcam A2 datasheet (2013)

[6] P. Heinl, A. Rottmair, C. Körner, R. F. Singer, Adv. Eng. Mater. 9 (5), 360 (2007)

[7] J. F. Radavich, Superalloy 718 - Metallurgy and Applications, 229 (1989)

[8] A. Bauereiß, T. Scharowsky, C. Körner, J. Mater. Process. Tech. 214 (11), 2522 (2014)

[9] E. Attar, C. Körner, J. Colloid Interf. Sci. 335 (1), 84 (2009)

[10] E. Attar, C. Körner, Int. J. Heat Fluid Fl. 32 (1), 156 (2011)

[11] C. Körner, E. Attar, P. Heinl, J. Mater. Process. Tech. 211 (6), 978 (2011)

[12] C. Körner, M. Thies, T. Hofmann, N. Thürey, U. Rüde, J. Stat. Phys. 121 (1-2), 179-196 (2005)

[13] Matthias Markl, Regina Ammer, Ulrich Rüde, C. Körner, Comp. Eng. F. and Sci. (Submitted 2014)

[14] R. Ammer, M. Markl, U. Ljungblad, C. Körner, U. Rüde, ICMMES-2012 67 (2), 318 (2014)

[15] M. Markl, R. Ammer, U. Ljungblad, U. Rüde, C. Körner, ICCS 201318 (0), 2127 (2013)

[16] M. Gäumann, S. Henry, F. Cléton, J.-D. Wagnière, W. Kurz, Mater. Sci. Eng. A 271 (1-2), 232 (1999)

[17] H. Helmer, C. Körner, R. F. Singer, J. Mater. Res. (Submitted 2014)

[18] S. Mokadem, C. Bezençon, A. Hauert, A. Jacot, W. Kurz, Metall. and Mat. Trans. A 38 (7), 1500 (2007) 